\title{
Ruokaperunan imago—attribuutit ja merkitys
}

\author{
Terri Kupiainen \\ Maa-ja elintarviketalouden tutkimuskeskus/taloustutkimus,PL 3, 00411 Helsinki \\ Puh 09-50447236, fax 09-5631164. Email: terri.kupiainen@mttl.fi
}

\section{Tutkimuksen tausta ja tavoite}

Tässä tutkimuksessa tarkastellaan ruokaperunan laatu- ja tuotekuvaa kuluttaja-asiakkaan näkökulmasta. Tutkimus kuuluu Maa- ja elintarviketalouden tutkimuskeskuksen koordinoimaan vuosina 20002002 toteutettuun ja edelleen jatkuvaan "Perunan taloustutkimusohjelmaan", jossa on mm. perunan tuotantoon ja kauppaan sekä kuluttajakäyttäytymiseen liittyviä tutkimuksia. Useilla peruselintarvikkeilla on verraten alhainen tuotekuva, minkä on nähty liittyvän elintason kohoamiseen yleensä. Elintason kohotessa kuluttajat pyrkivät valitsemaan kalliimpia tuotteita ja elintarvikkeita, jolloin peruselintarvikkeet menettävät asemaansa. Käytännön kannalta kuluttajanäkökulmaan liittyvä keskeisin huoli on paikannettavissa siihen keskusteluun, jota on käyty kansanterveydestä ja ravitsemukseen liittyen. Ruokaperunaa on usein käytetty esimerkkinä imagoltaan heikosta tuotteesta. Tässä yhteydessä on kiinnitetty ehkä liikaakin huomiota pitkän aikavälin muutoksiin mm. perunan kulutuksessa. Tämän hetken tilannetta ajatellen voidaan perustellusti esittää, että peruna on pitänyt hyvin asemaansa kuluttajan ruokataloudessa (Järvelä 2001). Mutta millainen perunan imago on markkinoinnin näkökulmasta? Hylkäävätkö kuluttajat perunan ja siirtyvätkö sen trendikkäiden substituuttien käyttäjiksi? Kuinka markkinointia pitäisi kehittää, että vähittäismyymälöissä myytävä ruokaperuna vastaisi paremmin erilaisten kuluttajaryhmien tarpeita?

\section{Käsitteet, viitekehys ja rajaus}

Modernia kulutusta tarkastellaan usein kuluttajien elämäntapaan ja -tyyliin integroituneena. Esimerkiksi elämäntyylitutkimus korostaa nimenomaan tietoisten ja usein välineellistenkin valintojen merkitystä kuluttajakäyttäytymisessä. Vapaan valinnan markkinoilla tuotekuvat rakentuvat kuluttajan valittavana olevien tuotteiden suhteellisista eroista ja niiden kyvystä tyydyttää jotain tiettyä tarvetta tai halua. Tuote- tai merkkikuvan rakentaminen onkin muodostunut yritysten erityiseksi päämääräksi, koska katsotaan, että merkityksen rakentuminen tuotteen ja sen käyttäjän välille tapahtuu käyttämällä tietoisesti hyväksi imagoja, jotka heijastavat tuotteiden identiteettejä.

Imagotutkimukset ovat kehittyneet viimevuosina hyvin moneen suuntaan (Danesi 1998, Salomon 2001). Yleisesti voidaan sanoa, että tuotteissa olevat merkit vaikuttavat siihen kuinka kuluttajat reagoivat niihin sen perusteella, mihin kuluttajan erityisiin mieltymyksiin tuotteet viittaavat. Ruokaperunan imagoa on luontevinta lähestyä arkikokemusten kannalta. Kuluttajien tulkinnat viriävät havaintoympäristön merkkien vaikutuksesta esimerkiksi tunteina, ajatuksina ja toimintoina kokemusten kautta.

\subsection{Imagon käsite}

Imagot sisältävät mielikuvia toiminnoista ja toimintaprosesseista, käsitekarttoja asioiden keskinäisistä yhteyksistä sekä visuaalisia representaatioita (Danesi 1998, 76-78). Imagot ovat luonteeltaan affektiivisia. Imagoja ei voida samaistaa yksinomaan virheelliseen tietoon, koska ne ovat osa ihmismielen toimintoja: ajattelua, informaation käsittelyä ja muistamista. Esimerkkinä toimintoihin liittyvistä mielikuvista voisi olla mielikuva ruoanvalmistukseen liittyvistä tekijöistä, kuten vaivattomuudesta, työn miellyttävyydestä jne. Käsitekartat muodostuvat usein toiminnoista ja niihin liittyvistä keskinäisistä suhteista ja kuluttajien kokemuksiin liittyvistä assosiaatioista, mutta ne ovat pääasiassa tiedostamattomia. Visuaalisella representaatiolla tarkoitetaan esimerkiksi kuluttajan arviota siitä, millaiselta tuore tai maukas ruoka näyttää. Representaatiot liittyvät arvoihin ja kulttuuriin. Tärkeitä representaatioita liittyy mm. väreihin, koska ne kuljettavat ominaisuuksia, mielialoja ja tuntemuksia. Imagot voivat muodostua kuulon, hajuaistin, liikkeiden, makuhavaintojen, tuntoaistin ja tunteiden perusteella. Imagot voivat olla 
todellisia objekteja, mutta ne ovat usein kuvitelmia, abstrakteja tai kertomuksen tapaisia. Ihmisellä on esimerkiksi mielikuva millaiselta kuulostaa ukkonen, miltä kostea ruoho tuntuu ja millaiselta se tuoksuu, millainen on kalanhaju tai miltä hammastahna maistuu. Elintarvikkeita koskevat imagot liittyvät ääniin, tuoksuihin, makuihin tai tuntuun.

Toinen keskeinen ihmismielen toimintoihin liittyvä tekijä on asioiden nimittäminen ja luokittelu. Tuotteita koskeva kielenkäyttö nimeää ja luokittelee sekä muovaa tuotteita koskevia konventioita joko tiedostetusti tai tiedostamatta. Attribuutit kuvaavat tuotteiden tuottamia vaikutuksia kuluttajille. Tuoteattribuutit ovat suhdekäsitteitä, joiden tarkoituksena on synnyttää, muuttaa tai uudistaa kokemuksia ja näin vaikuttaa tuoteimagoon. Attribuutteja voidaan esittää sanallisessa ja kuvallisessa muodossa. Niiden ei kuitenkaan tarvitse perustua kuluttajien todellisiin kokemuksiin, sillä usein riittää se, että kuluttaja on halukas kokemukseen. Tuotteita kuvaavat attribuutit ovat markkinoinnin työkaluja, joilla asemoidaan tuotteita ja markkinoita. Markkinoinnissa attribuutti voidaan ilmaista myös USP-tyyppisillä lausumilla, jotka sisältävät sisään upotettuja käsitteitä. Esimerkiksi "Coce is it" tai vaikkapa "Rehellistä suomalaista ruokaa". Vastaanottaja ei usein analysoi viestin merkitystä vaan hyväksyy sen esitetyllä tavalla.

\subsection{Empiirinen toteutus}

Tuotteiden laatua ja tuotekuvaa voidaan tutkia usealla eri tavalla (Aaker 1991; Keller 1998). Usein tämän tyyppiset tutkimukset vaativat tutkittavien tuotemerkkien spesifiointia, mutta eräitä menetelmiä voidaan soveltaa myös ns. merkittömien tuotteiden tutkimiseen, jollainen tutkimuksen kohteena oleva ruokaperuna on. Tässä tutkimuksessa tarkastelun kohteeksi on otettu 1) tuotteeseen välittömästi liittyvä käyttäytyminen, 2) markkinointitoimenpiteet, 3) kuluttajan elämäntyyli ja 4) perunan imago. Näiden oletetaan vaikuttavan ja muovaavan ruokaperunan tuotekuvaa suhteessa muihin korvaaviin tuotteisiin ja palveluihin. Ruokaperunalla tarkoitetaan jalostamattomana raaka-aineena kuluttajamarkkinoilla myytäviä perunoita, jotka myydään irtomyynnissä tai pussitettuna myymälöissä. Tällä tavoin rajattuna erilaiset perunatuotteet, kuten pakasteet, eivät tule luokitelluiksi ruokaperunaksi.

Välittömään käyttäytymiseen kuuluvat ruoanvalmistus- ja perunankäyttötavat, ostotavat ja laatukokemukset. Markkinointiin liittyvinä kysymyksinä tarkasteltiin kuluttajan kokemuksia tuotteiden esillepanosta myymälöissä ja kokemuksia kampanjoista. Lisäksi tutkittiin pakkaustoivomuksia ja niihin liittyviä ostoaikomuksia. Kuluttajien elämäntapaa kuvaavina muuttujina käytettiin harrastuksia ja demografioita. Tässä seminaarissa esiteltävä tutkimuksen osa käsittelee ruokaperunan imagoa, jota tutkittiin tilanneperusteisesti suhteessa riisiin ja pastaan sekä perunatuotteisiin. Lisäksi perunaan liittyviä assosiaatiota mitattiin 33 attribuutin suhteen. Vastaavia attribuutteja on käytetty aiemmin pk-yritysten valmistamien jalostettujen tuotteiden tutkimuksessa (Kupiainen \& Peltomäki 2001). Ruokaan liittyviä valintoja on tutkittu myös piirreanalyysin avulla (Salomon 2001). Tässä tutkimuksessa kuva-analyysin ideaa sovellettiin lomaketutkimukseen siten, että kysymyslomakkeessa esitettiin perunan kuva, ja vastaajia pyydettiin oman tunteensa perusteella arvioimaan, miten hyvin kukin attribuutti kuvasi ruokaperunaa.

\section{Analyysimenetelmät ja aineisto}

Tutkimus on survey-tyyppinen lomakekysely, joka lähetettiin satunnaisotantaan perustuen 3300: 1le 2070-vuotiaalle kuluttajalle. Kyselyn palautti $30 \%$ ensimmäisen postituksen jälkeen. Uusintapostituksia ei suoritettu. Tutkimusaineistona on näin ollen noin 1000 palautunutta ja tutkimukseen hyväksyttyä lomaketta. Aineistoa on analysoitu kvantitatiivisilla luokittelumenetelmillä ja monimuuttujamenetelmillä (faktorointi, klusterointi ja graafinen kuvaus). Lisäksi kvantitatiivisten menetelmien tuloksia havainnollistetaan Greimasin kehittämän semioottisen neliön avulla. Semioottista neliötä on käytetty varsin yleisesti markkinoinnin tutkimuksessakin jo 80-luvulta alkaen, mutta sitä on sovellettu haastatteluaineistojen ja mainonnan tutkimuksessa. Sen sijaan ns. kvantitatiivisten lomakeaineistojen tutkimuksessa Greimasin neliötä ei juurikaan ole aikaisemmin käytetty. Menetelmän etuna on erityisesti se, että sen avulla voidaan tutkia käsitteiden keskinäisiä suhteita ja näiden suhteiden synnyttämiä loogisia seurauksia (Floch 1988; Forskåhl \& Valtonen 1993). 
Tutkimukseen vastanneista $37 \%$ oli miehiä. Vastanneista $61 \%$ asui kaupunkien keskustoissa tai taajamissa. Maaseudun haja-asutusalueella asuvia tutkimukseen osallistuneista oli vain $20 \%$. Noin puolella vastaajista oli korkeakoulu, ammattikorkeakoulu tai opistotasoinen koulutus. Vastaanneista 70 $\%$ oli alle 55-vuotiaita. Aikuistalouksia oli $50 \%$ ja lapsiperheitä $41 \%$. Eläkeikäisiä oli $16 \%$. Perheen yhteenlaskettujen tulojen jakaumassa yli 200000 mk vuodessa ansaitsevien osuus oli $44 \%$.

\section{Tulokset}

Tutkimuksen mukaan perunan tuotekuva näyttää hyvältä. Tutkimukseen osallistuneiden talouksissa valmistetaan ruokaa päivittäin (51 \% ) ja vastanneet käyttivät ruokaperunoita melko runsaasti päivittäisessä kotiruoan valmistuksessa. Perunan käyttötottumukset vaihtelevat kuitenkin selvästi eri kuluttajaryhmissä. Perunan tuotekuvaa ja imagoa voidaan yleisesti pitää hyvinä etenkin jos asiaa katsotaan ravitsemuksen ja hyötynäkökulman kannalta. Kuluttajaryhmien välisessä vertailussa esimerkiksi perunan terveellisyysmielikuva liittyy siihen kuluttajaryhmään, joka valmistaa ruokaa päivittäin. Toisaalta myös ne, jotka eivät valmista usein aterioita ruokaperunoista nimeävät ne tästä huolimatta enemmän terveelliseksi kuin epäterveelliseksi. Kuluttajien huonot kokemukset päivittäistavaramyymälöiden esillepanon kunnosta ja visuaalisesta laadusta liittyvät sellaisten kuluttajien laatukokemuksiin, joilla on muita suurempi taipumus korostaa perunoiden elämyksellisiä aspekteja (attribuuttien ulottuvuudet ja merkitysrakenne kuvioissa 1 ja 2).

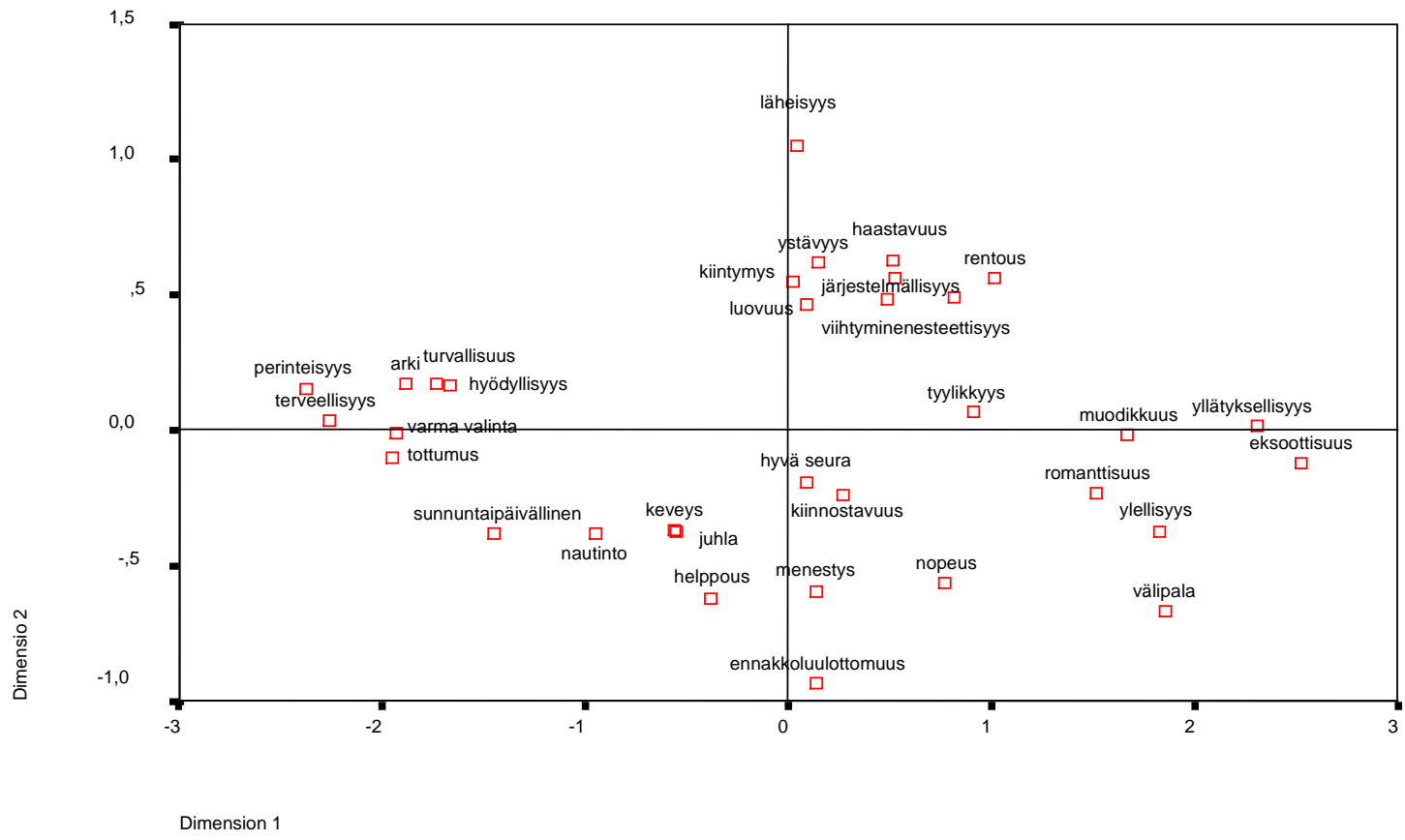

Kuvio 1. Attribuuttien ulottuvuudet: MDS-kartta redusoimattomista muuttujista. 


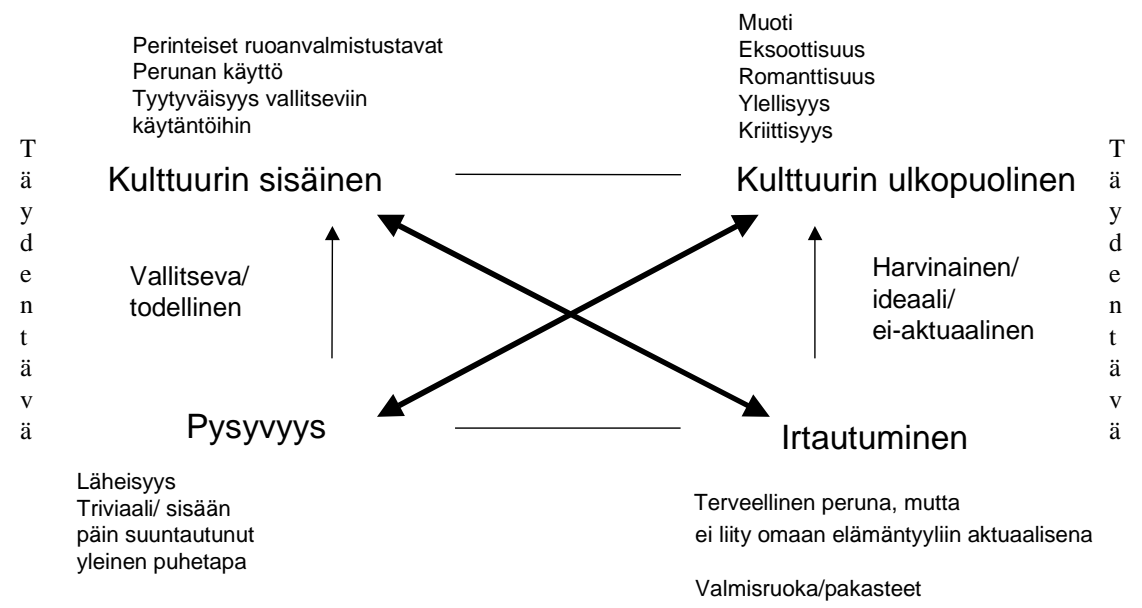

Kuvio 2. Vallitsevan kulttuurin näkökulmasta tapahtuva merkitysten muodostuminen.

\section{Johtopäätökset}

Ruokaperunalla on vakaa asema suomalaisen kuluttajan keittiössä. Tästä näkökulmasta tutkimukseen osallistuneet kuluttajat eivät todennäköisesti tule lisäämään perunan käyttöä talouksissaan kovinkaan paljon tulevaisuudessa. Tutkimuksen tulokset eivät myöskään täysin tue niitä väitteitä, joiden mukaan perheet valmistaisivat lämpimiä aterioita kotonaan vain viikonloppuisiin. Sen sijaan laadullisia ja esteettisiä eroja ateriakäytännöissä, ruoanvalmistustavoissa ja ruokalajien valinnoissa varmasti on eri kuluttajaryhmien välillä. Tutkimuksessa tuli selvästi esille eräitä markkinointiin liittyviä näkökohtia, jotka liittyvät mm. perunoiden pakkaamiseen ja kauppalaadun kehittämiseen sekä tuotekuvan kehittämiseen muutoinkin. Attribuuttianalyysin tulokset viittaavat siihen, että osa kuluttajista hyötyisi sellaisesta kohderyhmämarkkinoinnista, jossa kiinnitetään nykyistä enemmän huomiota arjesta poikkeavien merkitysten rakentamiseen ruokaperunoille esimerkiksi erikoisperunamarkkinoilla. Toisaalta aineiston valikoituneisuudesta johtuvat epävarmuustekijät saattavat vaikuttaa jonkin verran tuloksiin.

Kuviosta 2 voidaan saada selville se, millaista reittiä pitkin kuluttajan merkityksenantoprosessi etenee. Vallitsevan perunan käyttöön liittyvän ruoanvalmistuskulttuurin ulkopuolisten tekijöiden mukaantulo kuluttajan kokemuksiin, merkitsee yleensä irtautumista entisestä. Irtautuminen ei kuitenkaan tapahdu sattumanvaraisesti, vaan se etenee loogisesti määräytyvien vaiheiden kautta eivätkä kaikki siirtymät ole mahdollisia. Merkityksenannon prosessi on luonteeltaan generatiivinen eli uutta tuottava, mikä tarkoittaa, että se ei koskaan palaa täysin samaan lähtöpisteeseen mistä tarkastelu alkaa sen vuoksi, että kategorioiden sisältö muuttuu. Analyysi ei tuota suoria vastauksia ja yksinkertaisia ohjeita, vaan valaisee niitä valinnan mahdollisuuksia ja kehittämisen suuntia, jotka pitäisi pystyä käymään läpi kommunikaation takia ennen kuin uudet merkitykset syntyvät. Markkinoinnille tämä merkitsee sitä, että markkinoija joutuu jatkuvasti ikään kuin uuteen keskusteluun kuluttajan kanssa, jolloin vanhojakin käsitteitä olisi kyettävä tarkastelemaan uudessa valossa.

\section{Lähteet:}

Aaker, D. 1991. Managing Brand Equity. Capitalizing on the Value of a Brand Name. The Free Press.

Danesi, D. 1998. Sign, Thought, and Culture. Volume 4 in Series: Media, Communication and Culture Studies. Toronto.

Floch, J-M. 1988. The Contribution of Structural Semiotics to The Design of a Hypermarket. International Journal of Research in Marketing vol 4, 3.

Forskåhl, T. \& Valtonen, A. 1993. Semiotics as part of creative strategy, teoksessa Acta Semiotica Fennica, toim. Eero Tarasti.

Järvelä, K. 2001. Potaton is basic food - consumers' views and expectations concerning potato's quality. Unpublished manuscript. National Consumer Research Centre.

Keller, K. 1998. Strategic Brand Management: Building, Measuring, and Managing Brand Equity. Prentice Hall. 
Kupiainen, T. \& Peltomäki M. 2001. "Two Approaches to Affective Experiences and Product or Brand Identity: Value and Product”. AMS_WMC 2001 Proceedings. Academy of Marketing Science, Tenth Biennial World Marketing Congress June 28-July 1, 2001.

Salomon, M. 2001. Narrating the Branded Self: A Gestalt Perspective on Symbolic Consumption. Luento kutsuttuna esitelmöitsijänä. ISI kesäkongressit/ International Summer Institute for Semiotic and Structural Studies/Management Semiotics: The Narrated Self in Markets and Organisations 10.6-12.6-2001. 